\title{
Relações interétnicas: (des)encontros entre Kaingang e imigrantes holandeses no século XIX em territórios das bacias hidrográficas Taquari-Antas e Caí, Rio Grande do Sul
}

\author{
Interethnic relations: crossroads between Kaingang and \\ dutch immigrants in the nineteenth century in territories of \\ Taquari-Antas and Cai hydrographic basin, Rio Grande do Sul
}

\author{
Luís Fernando da Silva Laroque ${ }^{1}$ \\ Tiago Weizenmann ${ }^{1}$ \\ Jéferson Luís Schäeffer ${ }^{1}$
}

DOI: http://dx.doi.org/10.20435/tellus.v0i0.556

\begin{abstract}
Resumo: Os territórios das Bacias Hidrográficas do Taquari-Antas e Caí inserem-se no nordeste do Estado do Rio Grande do Sul. Foram formadas pelas movimentações de grupos indígenas, africanos escravizados, europeus e seus descendentes, compondo um mosaico étnico e cultural diversificado. O estudo tem como objetivo analisar as relações estabelecidas entre grupos distintos que se movimentaram pelo mesmo espaço no século XIX, em particular, envolvendo relações entre indígenas Kaingang e imigrantes holandeses. No século XIX, os espaços entre o planalto sul-rio-grandense e as Bacias Hidrográficas do Taquari-Antas e do Caí compreendiam parte do tradicional território Kaingang, cujo grupo passou a manter relações de conflito ou aliança com o elemento europeu a partir da introdução de colonos que compunham as frentes de expansão criadas pelo Estado Nacional Brasileiro. Os imigrantes holandeses, introduzidos na segunda metade do século XIX, compuseram parte das referidas frentes de expansão, sendo instalados em colônias em formação na Província de São Pedro do Rio Grande do Sul. Nesse contexto colonizatório, ocorreram contatos interétnicos entre os referidos agentes históricos, cujas relações, na maior parte das vezes conflituosas, tiveram significados culturais distintos para cada um dos grupos.
\end{abstract}

Palavras-chave: Santa Maria da Soledade; conflitos interétnicos; Kaingang; holandeses.

Abstract: Taquari-Antas and Caí Hydragraphic Basin are located in the northeast of the State of Rio Grande do Sul, and were formed by the movements of

Universidade do Vale do Taquari (Univates), Lajeado, Rio Grande do Sul, Brasil. 
indigenous groups, enslaved Africans, Europeans and their descendants, composing a diverse ethnic and cultural mosaic. The study aims to analyze the relationships established between distinct groups that moved around the same space in the nineteenth century, in particular, involving relations between Kaingang natives and Dutch immigrants. In the nineteenth century, the spaces between the plateau in the south of Rio Grande do Sul and the Hydrographic Basins of Taquari-Antas and Caí were part of the traditional Kaingang territory, which began to maintain relations of conflict or alliance with the European element from the introduction of settlers that formed the fronts of expansion created by the Brazilian National State. The Dutch immigrants, introduced in the second half of the nineteenth century, formed part of these fronts of expansion, being installed in colonies in formation in the Province of São Pedro of Rio Grande do Sul. In this colonial context, interethnic contacts took place between the mentioned historical agents, whose relations, most of the times conflicted, had different cultural meanings for each of the groups.

Keywords: Santa Maria da Soledade; interethnic conflicts; Kaingang; dutch.

\section{INTRODUÇÃO}

A Província de São Pedro do Rio Grande do Sul se constituiu a partir da imigração de grupos étnicos distintos e das migrações internas promovidas por esses grupos, tais como: indígenas, africanos e europeus, que compuseram um mosaico étnico e cultural bastante distinto. O presente estudo tem como limite temporal o século XIX e, como demarcação espacial, territórios das Bacias Hidrográficas Taquari-Antas e Caí ${ }^{2}$ ambas localizadas no nordeste do Estado do Rio Grande do Sul, abrangendo as Províncias geomorfológicas Planalto Meridional e Depressão Central (SECRETARIA DO AMBIENTE E DESENVOLVIMENTO SUSTENTÁVEL [SEMA], 2017).

A problemática proposta neste estudo é apresentar o processo de ocupação e de povoação do território correspondente às Bacias Hidrográficas Taquari-Antas e Caí, no século XIX. O objetivo do trabalho é analisar as relações estabelecidas a partir de grupos distintos, que se movimentaram num espaço comum, em particular, envolvendo as relações entre indígenas Kaingang e imigrantes holandeses.

O tradicional território Kaingang no século XIX compreendia os espaços entre o planalto sul-rio-grandense e as Bacias Hidrográficas do Taquari-Antas e Caí, os

2 Conforme SEMA (2017), as Bacias Hidrográficas Taquari-Antas e Caí inserem-se na região hidrográfica do Guaíba e atendem pelos códigos G040 e G030, respectivamente. 
quais eram ocupados pelo Grupo dos Jê-Meridional (BECKER, 1995). Nessa mesma conjuntura, por parte do Estado Nacional Brasileiro, houve uma introdução significativa de grupos europeus provenientes de diferentes nacionalidades, a exemplo dos holandeses, que adentraram a Província, na segunda metade do século XIX.

O método do presente estudo está baseado numa análise qualitativa dos dados pesquisados, embasados em aportes teóricos de cultura, etnicidade e identidade, de autores como Barth (2000), Oliveira (1976), Laraia (2003) e Woodward (2004). Igualmente, recorreu-se ao levantamento de dados coletados em revisões bibliográficas, provenientes de obras de autores que tratam do processo de ocupação da Província de São Pedro do Rio Grande do Sul, e as relações interétnicas estabelecidas entre indígenas e colonizadores. Da mesma forma, fez-se uso de fontes documentais, oriundas de Arquivos Históricos do Estado do Rio Grande do Sul.

\section{AGENTES DA HISTÓRIA REGIONAL: GRUPOS ÉTNICOS INVISIBILIZADOS NO PROCESSO DE OCUPAÇÃO DAS BACIAS HIDROGRÁFICAS TAQUARI- ANTAS E CAÍ}

A historiografia tradicional do Rio Grande do Sul invisibilizou grupos étnicos, que tiveram papel relevante na constituição de espaços territoriais das Bacias Hidrográficas Taquari-Antas e Caí, colocando em evidência alguns, mas sem ao menos mencionar tantos "outros", o que resultou numa lacuna histórica no processo de ocupação do referido território.

Nesse sentido, grupos indígenas culturalmente diversos, provenientes de distintas etnias e troncos linguísticos, são minimizados no discurso popular, no que diz respeito ao processo colonizatório. Na maioria das vezes, sua lembrança é associada a uma situação conflituosa, em que o "outro" é visto como danoso, invasor e perturbador. Esses conflitos foram desencadeados em função do contato interétnico entre indígenas e os integrantes das frentes de expansão ${ }^{3}$, ou seja,

3 Sobre "frentes de expansão", entende-se que foram criadas pelo governo da Província de São Pedro do Rio Grande do Sul - seguindo o projeto de desenvolvimento do Estado Nacional Brasileiro do século XIX - com a finalidade de colonizar e tornar o território mais rentável. Estudo de Martins (1997), sobretudo para Amazônia, traz a noção de "frentes de expansão" relacionada à expansão do capitalismo e a um espaço de fricção interétnica. 
através da introdução de estrangeiros imigrantes e a expropriação territorial do elemento nacional, os indígenas, sejam eles, Charrua, Minuano, Guarani, Xokleng/ Laklãno e Kaingang.

Igualmente, a presença de africanos na Província de São Pedro do Rio Grande do Sul recebeu pouco espaço na historiografia tradicional. Trabalhos recentes, como o de Christillino (2004), Gregory (2015) e Pires (2016), reportam-se à presença expressiva de escravizados em fazendas e posteriores colônias do século XIX, em territórios da Bacia Hidrográfica do Rio Taquari. Da mesma forma, Correa (2006) menciona em seu trabalho, o multiculturalismo no Rio Grande do Sul do século XIX, a imigração forçada de escravizados africanos, inclusive, a existência de quilombos, que compuseram parte dessa paisagem cultural diversificada.

A imigração europeia, no tocante ao processo de ocupação da Província de São Pedro do Rio Grande do Sul e suas posteriores colônias, é a mais presente no discurso popular, embasada num sentimento expressivo de pertencimento e de continuação das práticas dos antepassados, oriundas do além-mar. Portugueses, açorianos, espanhóis, alemães, italianos, além de muitos outros formaram a conjuntura socioeconômica e política do século XIX.

Nesse sentido, faz-se necessária uma reflexão acerca do que se entende a partir da expressão generalizante "imigração alemã". Os resultados desta pesquisa expressam que não se tratava tão somente de alemães, mas, sim, de uma gama de imigrantes oriundos de diferentes regiões da Europa, com aspectos culturais distintos, tais como língua, crenças e costumes.

Através dos registros de entrada de imigrantes no segundo período da imigração alemã (1848-1874), presentes nos códices 234 e 299 do Arquivo Histórico do Rio Grande do Sul, notou-se a incorporação de uma série de imigrantes provenientes de diferentes nacionalidades para além da alemã, como austríacos, belgas, dinamarqueses, franceses, luxemburgueses, holandeses e suíços.

Como exemplo dessa heterogeneidade, mencionamos a entrada da família Alberg-com variantes para Abeck/Abegg, no Rio Grande do Sul, oriunda da França.

ALBERG, Francisco, 17-21, cas.; Catharina, 0-21, cas.; Catharina, 0-7; Leopoldo, menor de 2 anos; Luiz, menor de 2 anos; franceses.; chegada de Rio Grande neste Porto: 28-11-1858, emb.: Marquês de Caxias (vapor); destino: Nova Petrópolis. [...]. (CÓDICE 234, n. 6-10, p. 64, grifo nosso). 
Em relação a esses grupos de imigrantes europeus, há intensa necessidade de distinguir a proveniência das famílias: qual o país de origem, qual a instrução religiosa, qual a variação linguística, entre outros aspectos, para notar a heterogeneidade dos grupos que compuseram a expressão "imigração alemã", na qual há muito mais do que parece à primeira vista. As informações acerca da imigração alemã não estão defasadas, mas há muito ainda a ser investigado e que necessita de problematização.

Nesse sentido, cabe destacar as considerações de Barth (2000), quando conceitua os grupos étnicos como populações que se autoperpetuam biologicamente, compartilhando valores culturais semelhantes e que interagem e se comunicam mutuamente, identificando-se e sendo identificados como parte do grupo.

Referente à composição étnica no processo de ocupação dos entornos das Bacias Hidrográficas Taquari-Antas e Caí, o protagonismo de indígenas, negros escravizados e imigrantes propiciou a formação de um ambiente multicultural intensamente heterogêneo, marcado por encontros e desencontros culturais, tendo em vista que cada um desses grupos étnicos procurava manter seus elementos culturais. Conforme Correa (2006), o processo que deu sequência às relações interculturais nesse espaço agiu de forma a instituir uma cultura padrão que servisse de exemplo às demais, homogeneizando, a longo prazo, as minorias étnicas.

Segundo Laraia ([1986] 2003), os sistemas culturais estão em constante processo de mudança. Os contatos interétnicos são fatores que instigam transformações mais bruscas dentro de um grupo social. Nesse sentido, essas mudanças assumem um caráter acumulativo, conservando-se antigas práticas, apesar da aquisição de novas.

Da mesma forma, a continuidade das práticas culturais dos referidos grupos requereu uma adaptação cultural em relação ao meio que os circundava. Assim, podemos dizer que os imigrantes, além de colonizadores, também eram colonizados pelas novas terras e pelas práticas ali existentes e utilizadas. Laraia ([1983] 2003) chama atenção, afirmando que esse processo é possível mediante a troca do equipamento cultural pelo desenvolvido no novo habitat. Neste sentido, suas ações estarão limitadas ao material cultural ali fornecido.

A intenção do estudo é analisar as relações interétnicas entre indígenas Kaingang, tradicionais ocupantes do território em questão, e os imigrantes 
holandeses, generalizadamente considerados como alemães, provenientes do segundo período da imigração alemã (1848-1874). Em vista disso, vale salientar que, apesar da especificidade étnica, ambos os grupos se movimentaram num espaço comum, mantendo e compartilhando relações, conflituosas ou não, numa fase de intensas mudanças no sul do Brasil.

Conforme Becker (1995), os espaços entre o planalto sul-rio-grandense e as Bacias Hidrográficas Taquari-Antas e Caí eram tradicionais territórios de populações indígenas com predominância da tradição arqueológica Taquara ou Proto Jê, conforme demonstram estudos mais recentes (WOLF, 2016). De acordo com Laroque (2009), o grupo étnico Kaingang pertence ao Grupo Jê Meridional, que possuía como tradicional território, desde o oeste da Província de São Paulo, norte e oeste da Província do Paraná, oeste da Província de Santa Catarina até ambas as margens da Bacia Hidrográfica do Jacuí e Lago Guaíba, na Província de São Pedro do Rio Grande do Sul, estendendo-se também à região de Misiones, na Argentina.

Deve-se ressaltar que, no século XIX, essas extensões formavam um amplo território. Apesar de serem separados por cursos d'água, tais como bacias e rios, as parcialidades Kaingang eram interligadas por laços de familiaridade e de reciprocidade. Da mesma forma, o referido grupo mantinha uma interação bastante íntima com o meio/natureza, que, além de garantir a subsistência, assegurava a continuidade de suas práticas culturais.

Essa concepção cultural e territorial entraria em choque com o modelo de jurisdição do Império brasileiro, que seguia uma tendência exploratória e considerava as extensões territoriais como pertencentes ao Estado; portanto poderiam ser utilizadas para o projeto colonizador privado. Sendo assim, as relações entre indígenas Kaingang e imigrantes europeus foram estabelecidas a partir do momento em que o Governo Imperial passou a organizar frentes de expansão em direção às matas, até então consideradas como "vazias", na intenção de povoar o território e torná-lo mais rentável. Nesse contexto, os imigrantes holandeses aparecem como integrantes dessas frentes de expansão, envolvendo-se numa teia de relações com o "outro".

A presença holandesa no Brasil, grosso modo, é associada às invasões holandesas do século XVI, quando era disputado o controle do açúcar, mas esta não 
foi a última vez ${ }^{4}$ em que os holandeses estiveram em terras brasileiras. A partir da presente análise, é possível evidenciar uma presença holandesa significativa no século XIX - como imigrantes, cuja fase histórica está generalizada sob a periodização conhecida como "imigração alemã".

A introdução de holandeses no Brasil esteve ligada ao já mencionado projeto de desenvolvimento do Estado Nacional Brasileiro, tendo sido recrutados por diversos agentes colonizadores na Europa, a partir da segunda metade da década de 1850, com o intuito de povoar as colônias recém-criadas no Brasil, nas Províncias do Espírito Santo, Santa Catarina e Rio Grande do Sul. Roos e Eshuis (2008) atestam que, mais precisamente entre os anos de 1858 e 1862, mais de 700 holandeses teriam emigrado para o Brasil.

Com base em registros de entrada desses imigrantes e dos assentos de batismos, casamentos e óbitos, oriundos das entidades eclesiásticas e dos cartórios das comunidades às quais pertenciam, foi possível constatar que a maior parte dos imigrantes que foram destinados à Província de São Pedro do Rio Grande do Sul era oriunda das Províncias holandesas de Gelderland e Zeeland.

Como exemplo de registros eclesiásticos, apresentamos o assento de casamento do imigrante holandês Christian te Roller, proveniente da Comunidade Evangélica (IECLB) de São Vendelino, Rio Grande do Sul. O registro escrito no idioma alemão e datado do ano de 1876 evidencia a nacionalidade holandesa do nubente, nascido em Eibergen, na província de Gelderland, conforme segue:

CHRISTIAN TE ROLLER, Sohn des Heinrich te Roller aus Eibergen, Holland, und Henricka geb. Abenk, von da mit CATHARINA TAFFE, Tochter des Carl Taffe, aus Hessen, und Philippine geb. Haas, werden am heutigen Tage, dem (18) achtzehnten April (1876) achtzehnhundertsechs und siebzig nach dreimaligem Aufgebot getraut. (IGREJA EVANGÉLICA DE CONFISSÃO LUTERANA NO BRASIL [IECLB], [s.d.], grifos nossos) $)^{5}$.

4 Igualmente, não deixamos de mencionar os imigrantes holandeses oriundos da onda migratória do século XX, os quais formaram colônias holandesas existentes até os dias atuais no Brasil, conforme trata a obra de Riel e Zart (2011), sobre a imigração holandesa de Não-Me-Toque, RS.

5 CHRISTIAN TE ROLLER, filho de Heinrich te Roller de Eibergen, Holanda, e Henricka nascida Abenk, com CATHARINA TAFFE, filha de Carl Taffe, de Hessen, e Philippine nascida Haas, serão casados neste dia, ao (18) décimo oitavo de abril de (1876) mil oitocentos setenta e seis (tradução dos autores). 
Na Província de São Pedro do Rio Grande do Sul, os holandeses foram instalados com maior expressividade nas colônias ${ }^{6}$ recém-formadas de Santa Cruz (1849), Santa Maria da Soledade (1855), Santo Ângelo (1857) e Nova Petrópolis (1858). Duas dessas colônias, localizadas nas delimitações da Bacia Hidrográfica do Caí.

No final do século XIX, ou seja, mais precisamente entre as décadas de 1880 e 1900, notou-se, na documentação manuseada, que esses imigrantes promoveram migrações internas, ocupando uma série de municípios que atualmente correspondem às delimitações da Bacia Hidrográfica Taquari-Antas, acompanhando o avanço do excedente populacional das primeiras colônias, cuja fronteira agrária, conforme Christillino (2004), se direcionava à região atualmente denominada de Vale do Taquari.

\section{3 ÀS MARGENS DO RIO CAÍ: A EFÊMERA COLÔNIA DE SANTA MARIA DA SOLEDADE}

A “imigração alemã" para o sul do Brasil teve início após a independência do Brasil, sendo associada essencialmente à ocupação de terras "devolutas"7 através da colonização. Roche (1969) dividiu essa fase de imigrações em três períodos durante a jurisdição imperial: 1824-1847, 1848-1874 e 1874-1889.

Inicialmente, a imigração foi de caráter oficial, tendo o Governo Brasileiro atraído os colonos europeus mediante a promessa de inúmeras vantagens. Nessas condições, competia ao Império organizar o recrutamento ${ }^{8}$ de colonos na Europa, cobrir a viagem, garantir a liberdade de culto, conceder-lhes terras e mantê-los, pelo menos no período inicial. A partir de 1830, a imigração foi interrompida e retomada após 1845, mediante a pacificação da Província de São Pedro do Rio Grande do Sul, longamente atormentada por uma crise política.

6 De acordo com Roche (1969), tratavam-se de espaços criados para estabelecer imigrantes europeus, de caráter oficial ou privado. As colônias deviam ser autossuficientes e baseadas na pequena propriedade rural.

7 Conforme Christillino (2004), tratava-se de extensões territoriais que não se achavam sob domínio de particulares, ou seja, mesmo que ocupadas por populações indígenas, estavam aptas a serem concedidas na forma de sesmarias, e, mais tarde, após a Lei de Terras de 1850, a particulares, para colonização e comercialização.

8 Conforme Roche (1969), o recrutamento de colonos foi feito pelo Major Schaeffer, agente do Governo Brasileiro na Europa, que era conhecido de Dom Pedro I e já havia engajado voluntários para os batalhões anos antes. 
No segundo período da imigração, entrou em vigor a Lei Geral de 18 de setembro de $1850^{\circ}$, que regulamentava a aquisição de terras devolutas, o que possibilitou a fundação de numerosas colônias particulares. O principal sistema que vigorou para fazer o recrutamento de colonos nesse período foi o contrato que introduziu levas significativas de imigrantes nas colônias em formação.

A instalação dessas colônias, nas quais se desenvolvia uma cultura de subsistência e que se limitavam a uma mínima intervenção externa, colaborava com o plano expansionista do Governo da época. Da mesma forma, a fundação de colônias favorecia a abertura de estradas, que futuramente seriam úteis para o deslocamento do excedente. Nesse sentido, as primeiras colônias foram instituídas através da iniciativa imperial, originando colônias de caráter oficial e, num segundo momento, ficaram a cargo da Província, em parceria com a iniciativa privada, fundando colônias particulares.

Segundo madame Marie van Langendonck ${ }^{10}$ ([1862] 2002), a Colônia de Santa Maria da Soledade foi fundada após o governo imperial conceder uma extensão de terras às margens do Rio Caí ${ }^{11}$, conforme mapa (Figura 1), ao vice-cônsul da França em Porto Alegre, o conde Paulo de Montravel. De acordo com o contrato ${ }^{12}$ celebrado entre o Império e o referido Paulo de Montravel, este solicitara a compra de uma área de terras "nas vizinhanças do rio Cahy", em 1854, com a finalidade de introduzir colonos suíços católicos, num período de três anos.

9 De acordo com Christillino (2004), a Lei de Terras de 1850 proibia a obtenção de terras através da posse, permitindo, a partir daquele momento, a aquisição de terras devolutas somente através da compra. Igualmente, a lei previa que posseiros legitimassem suas posses de acordo com o prazo estipulado. Neste sentido, Christillino (2004) concluiu que a referida lei foi fundamental no processo de expropriação de populações indígenas de seus territórios.

10 Marie Barbe Antoniette Rutgeerts van Langendonck, escritora e poetisa belga, emigrou para o Brasil no ano de 1857, instalando-se na Colônia de Santa Maria da Soledade, onde viveu por três anos. Em 1862, tendo já regressado à Bélgica, escreveu a obra "Une colonie au Brésil", registrando importantes experiências vividas durante o processo colonizatório da Província de São Pedro do Rio Grande do Sul.

11 Portanto, em espaços da Bacia Hidrográfica do Caí.

12 Contrato de 30 de dezembro de 1854. 
Figura 1 - Mapa das Colônias no Vale do Rio Caí - Século XIX

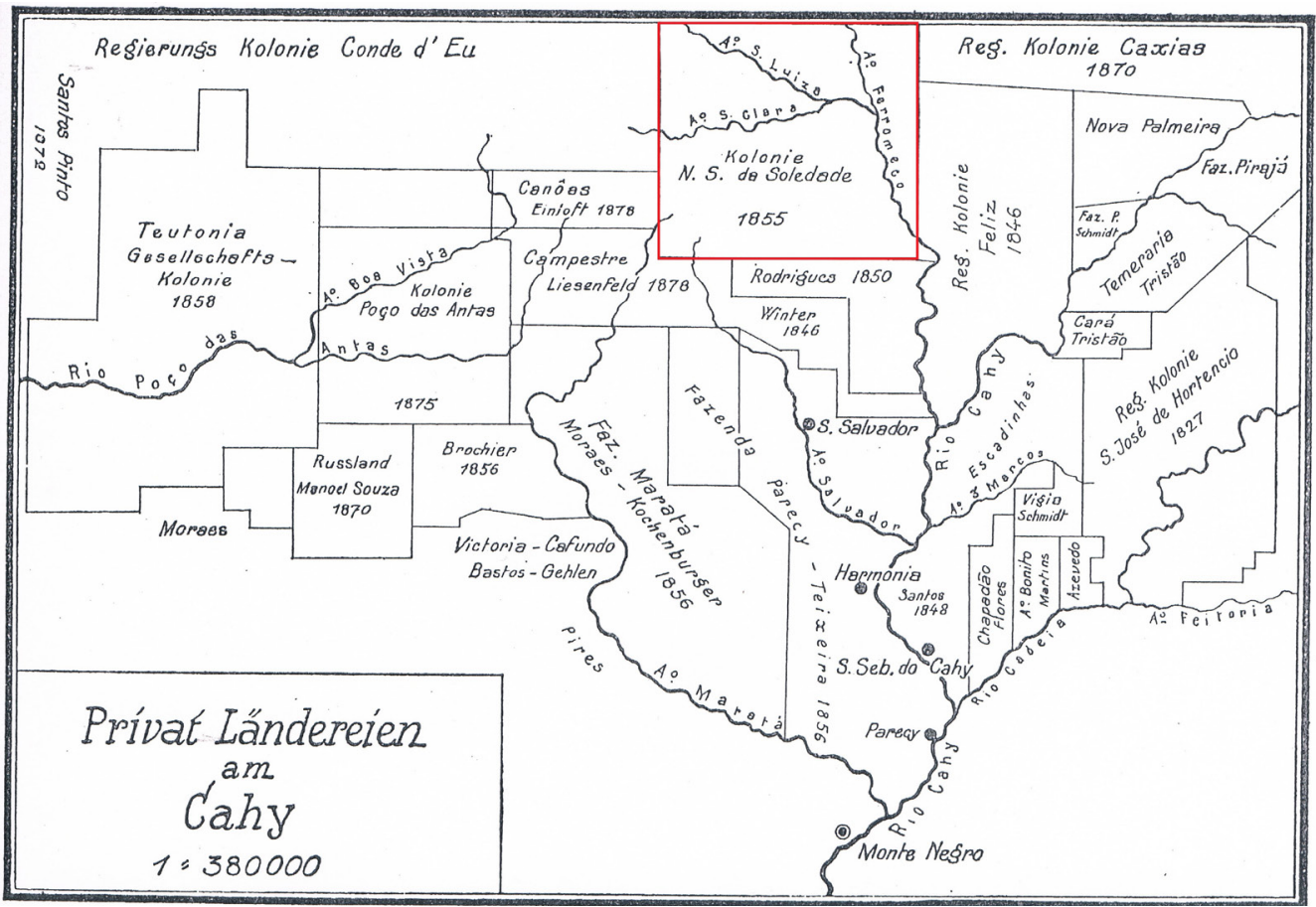

Fonte: Adaptação de Amstad ([1924] 1999, p. 113).

Comprometido com o Imperador do Brasil a colonizar as referidas terras, Montravel passou a introduzir colonos europeus, conforme relata a viajante belga acerca de sua chegada nas ditas extensões: "Éramos a terceira família que vinha habitar as quatro léguas quadradas que a Sociedade Montravel era obrigada a povoar em um dado tempo" (LANGENDONCK, [1862] 2002, p. 51).

Sobre o cotidiano dos primeiros colonos e sua relação com o meio, temos também os relatos atinentes à família Langedonck:

Nesse meio tempo, nossa cabana tinha sido concluída, mas estava construída no meio da colônia, e como o primeiro transporte de emigrantes tinha entrado em posse de terrenos afastados, estávamos sempre muito isolados. Apenas o terreno da frente da casa estava desmatado, a parte de trás ficava apenas alguns metros da floresta. (LANGENDONCK, [1862] 2002, p. 76).

Incapaz de introduzir os colonos no prazo estipulado, o empreendedor Montravel foi obrigado a modificar o contrato reiteradas vezes. Como exemplo 
citamos o contrato ${ }^{13}$ celebrado entre o Governo Imperial e o Conde de Montravel em 06/02/1855, no qual o prazo para a introdução dos colonos foi estendido para cinco anos, bem como, não foi delimitada a origem étnica dos imigrantes. A única exigência era que os colonos importados fossem "lavradores e gente do campo".

Em resposta às dificuldades, Montravel fundou a empresa de colonização "Montravel, Silveira e Cia.", com escritório na Antuérpia. A sociedade havia sido instituída através da associação com três sócios: Dr. Israel Soares de Barcellos, Dr. Dionísio de Oliveira Silveiro e João Coelho Barreto. A partir do Códice $313^{14}$ do Arquivo Histórico do Rio Grande do Sul, entende-se que a Colônia foi dividida entre seus sócios, formando quatro distritos: Distrito Barcellos, Distrito Silveiro, Distrito Coelho e Distrito Montravel.

A respeito do recrutamento de colonos com destino à Colônia de Santa Maria da Soledade, os registros do Códice $234^{15}$ evidenciam que 15 famílias desembarcaram no Porto de Rio Grande, em 05/09/1858. De origem prussiana, belga e holandesa, haviam sido introduzidas pela Sociedade Montravel, Silveira e Cia, que pagou as despesas de viagem. Uma das famílias listadas na relação é a família Dierings, natural da Província de Zeeland, na Holanda:

DIERINGS, João, 31-40, cas.; Cornelia, 31-40, cas.; Abrahão, 17-21; Carolina, 15-21; Miguel, 17-21; Pedro, 7-16; Adrianna, 8-14; Isaac, 0-6; Susanna, 0-7; hol.; chegada de Rio Grande neste Porto: 5-9-1858, emb.: Continentista (vapor); destino: Santa Maria da Soledade. Observações.: Provenientes de Antuerpia pelo Navio Monickenduca, Cap. Flick, até o no 50 contratados por Montravel Silveira e Cia que pagou suas despesas particularmente; de 50 em diante por conta do Governo (CÓDICE 234, n. 40-48, p. 43, 1858, grifo nosso).

Em relação ao processo de recrutamento de colonos, estando a Sociedade Montravel pressionada pelo prazo do contrato, "acabou apelando aos agentes colonizadores da Europa ${ }^{16 "}$. Nesse sentido, a viajante Langedonck emitiu fortes

${ }_{13}$ Contrato de 6 de fevereiro de 1855.

14 O Códice 313 arrolou os proprietários de terras na antiga Colônia de Santa Maria da Soledade. A relação de colonos ali residentes por volta de 1880, dividiu-se em dois volumes na sequência de quatro Distritos: Barcellos, Silveiro, Coelho e Montravel. O material não possui datação.

15 Códice 234 (1858), Livro de registros de colonos chegado à Província de São Pedro do Rio Grande do Sul (1857-1863).

16 Langendonck, [1862] 2002, p. 55. 
críticas ao processo de escolha desses colonos, enfatizando que os agentes europeus "[...] Ihes enviaram não a escória desta população, mas os piores dessa escória" (LANGENDONCK, [1862] 2002, p. 55). Igualmente, teriam sido introduzidos belgas recrutados de prisões e holandeses sem coragem moral e força física, que teriam vindo seduzidos pelos agentes de colonização na Holanda com o intuito de enriquecerem, mas se depararam com a inesperada precariedade da vida na colônia.

A mesma crítica é emitida em relação à religião, visto que o Conde de Montravel teria se comprometido a introduzir somente colonos católicos, o que não ocorreu, já que o número de protestantes era muito maior do que o de católicos. Ainda atesta que o próprio administrador da colônia era protestante, corrompendo a ideia inicial da preferência pelo culto católico.

Conforme a listagem ${ }^{17}$ de colonos residentes na antiga Colônia de Santa Maria da Soledade, a Sociedade Montravel introduziu, além de alemães, colonos austríacos, belgas, franceses, holandeses e suíços, sendo, mais tarde, notadas possessões de italianos. Essa gama de imigrantes, embora heterogênea entre si, movimentou-se num espaço comum. Assim, pode-se concluir que o meio agiu de forma preponderante nas relações interétnicas mantidas nessa conjuntura.

De acordo com Roche (1969), a Sociedade havia introduzido 1187 imigrantes, em 1859. Anos depois, o convênio entre o governo imperial e a Sociedade Montravel, Silveira e Cia foi rescindido, sendo a colônia assumida pela Província. Em 1876, foi fundada a Colônia de São Vendelino, cujas delimitações geográficas se estenderam sobre parte da antiga Colônia de Santa Maria da Soledade ${ }^{18}$, tendo como administrador, Eugênio Carrard.

No entanto a Colônia de Santa Maria da Soledade teve início muito antes da concessão da referida faixa de terras ao Conde de Montravel e a introdução de imigrantes europeus. Além desses imigrantes, há evidências de uma possível presença lusitana, visto que os lotes iniciais pertenciam a indivíduos

17 Códice 313, Livro de lotes da Ex-Colônia Santa Maria da Soledade.

18 Na atual divisão territorial, os municípios de São Vendelino, Barão e partes de Carlos Barbosa, localizados na Bacia Hidrográfica do Caí, Rio Grande do Sul, comporiam a Colônia fundada pelo Conde de Montravel. 
com sobrenomes de origem lusa, além dos grupos indígenas Kaingang, que, no século XIX, ali possuíam seu tradicional território. Langendock ([1862] 2002) mencionou ainda a presença de negros - escravizados e refugiados nas matas - e indígenas - aos quais se referiu como "civilizados" e "selvagens" que provocavam pilhagens. Sobre a presença indígena, mas não citando sua etnia, a Madame ressalta:

Não longe de nós, veio se estabelecer uma família indígena, composta por oito pessoas. Eram verdadeiros peles-vermelhas, de raça índia. A Sociedade empregava o marido, seus dois irmãos e os dois filhos de sua mulher, de quem ele era o segundo marido, no traçado de estradas e a abertura de picadas que separavam as colônias: eles haviam comprado duas, que cultivavam perfeitamente, por sua conta. (LANGENDONCK, [1862] 2002, p. 61).

Frente ao exposto, é possível perceber que os Kaingang, tradicionais ocupantes do referido território, tiveram seus espaços ameaçados pela introdução de imigrantes europeus, nesse caso, holandeses, que, de acordo com o projeto colonizador em vigor na Província, foram instalados na Colônia de Santa Maria da Soledade. Portanto o processo colonizatório avançou sobre as matas entendidas como "desabitadas" /"devolutas", não levando em consideração a presença indígena e seus respectivos aspectos culturais, provocando reiterados (des)encontros, conflituosos ou não, com o "outro".

\section{A IDEIA SOBRE O “OUTRO”: O CONFLITO COM A FAMÍLIA VERSTEEG}

Na colônia de Santa Maria da Soledade, (con)viver com grupos étnicos distintos parece ter sido algo corriqueiro, causando distintos tipos de relações. A partir da documentação manuseada, também é possível notar que a equidade étnica não foi levada em consideração pelo projeto colonizador, tendo em vista a heterogeneidade dos imigrantes europeus ali introduzidos. Mesmo assim, a língua e a confissão religiosa atuaram como fatores culturais para agrupamentos, promovendo a continuação das práticas culturais, mesmo que a terra natal estivesse distante no espaço.

É nesse sentido que se percebe a colônia de Santa Maria da Soledade como ponto de encontro de grupos que viviam em universos culturais distintos, comunicando-se a partir de línguas diferentes e fazendo uso de aparatos culturais 
específicos de cada grupo. Tendo como base Barth ([1969] 2000), entende-se que quanto maiores as diferenças culturais entre distintos grupos étnicos, menor é a interação étnica. Assim, a interação se dá em função da complementaridade de algumas características culturais.

Nos casos em que se armaram conflitos entre indígenas e imigrantes europeus, observa-se que houve entre eles um distanciamento cultural bastante expressivo nas formas de (vi)ver a si e os demais, muito maior se comparado aos demais grupos de imigrantes europeus introduzidos nessas extensões. Logo, esse ambiente - com tendências extremamente interétnicas - foi propício para o desenvolvimento de visões e imaginários pejorativos acerca dos indígenas, considerados como parte da natureza, desprovidos de racionalidade, portanto, algo não humano. Em termos de relações sociais, são considerados "selvagens", violentos, ou, simplesmente, "o outro". Resquícios dessa concepção são perceptíveis na carta que Mathias Franzen escreveu a seu cunhado Mathias Rockenbach, em 1832, fazendo menção a conflitos interétnicos ocorridos em territórios da Bacia Hidrográfica do Caí naquela conjuntura:

Wir wären ganz froh u. Glücklich, wenn ein großes Uebel nemlich die wilden Menschen nicht wären, die schon lange die Waldungen unsicher gemacht und schon 21 Deutschen Brüdern das Leben geraubt haben. [...] wenn sie nicht ihre Raub und

Mordsucht befriedigen Müßten. Es ist ihnen hauptsächlich um die Entwendung von Eisengeschirr zu tun. (VOLKSBLATT, 1934, grifo nosso) ${ }^{19}$.

Sendo a questão do território uma das principais justificativas para os conflitos entre indígenas e "civilizados", estes aumentaram em proporção, a partir da instituição das frentes de expansão pelo governo da Província de São Pedro do Rio Grande do Sul. Colonos, instalados compulsoriamente sobre assentamentos indígenas notaram a presença Kaingang como invasiva, enquanto estes, perdendo seus tradicionais territórios de forma cada vez mais efetiva, também desenvolveram uma concepção repulsiva acerca do elemento estrangeiro.

O mapa a seguir (Figura 1) traz uma relação de nove encontros interétnicos entre Kaingang e imigrantes europeus no século XIX, em regiões das colônias Feliz

19 Estaríamos muito contentes e felizes se não fosse um grande mal, isto é, se homens selvagens, que já desde muito tornaram os matos inseguros e roubaram a vida de 21 irmãos alemães. [...] se não tivessem que satisfazer o seu desejo de roubo e morte. Trata-se principalmente da busca de instrumentos de ferro (tradução dos autores). 
e Santa Maria da Soledade, que foram mencionados pelos autores Gansweidt (1946), Barbosa (1977), Mabilde (1983), Becker (1995) e Vedoy (2015).

Figura 2 - Mapa dos conflitos em regiões das Colônias de Feliz e Santa Maria da Soledade, no século XIX

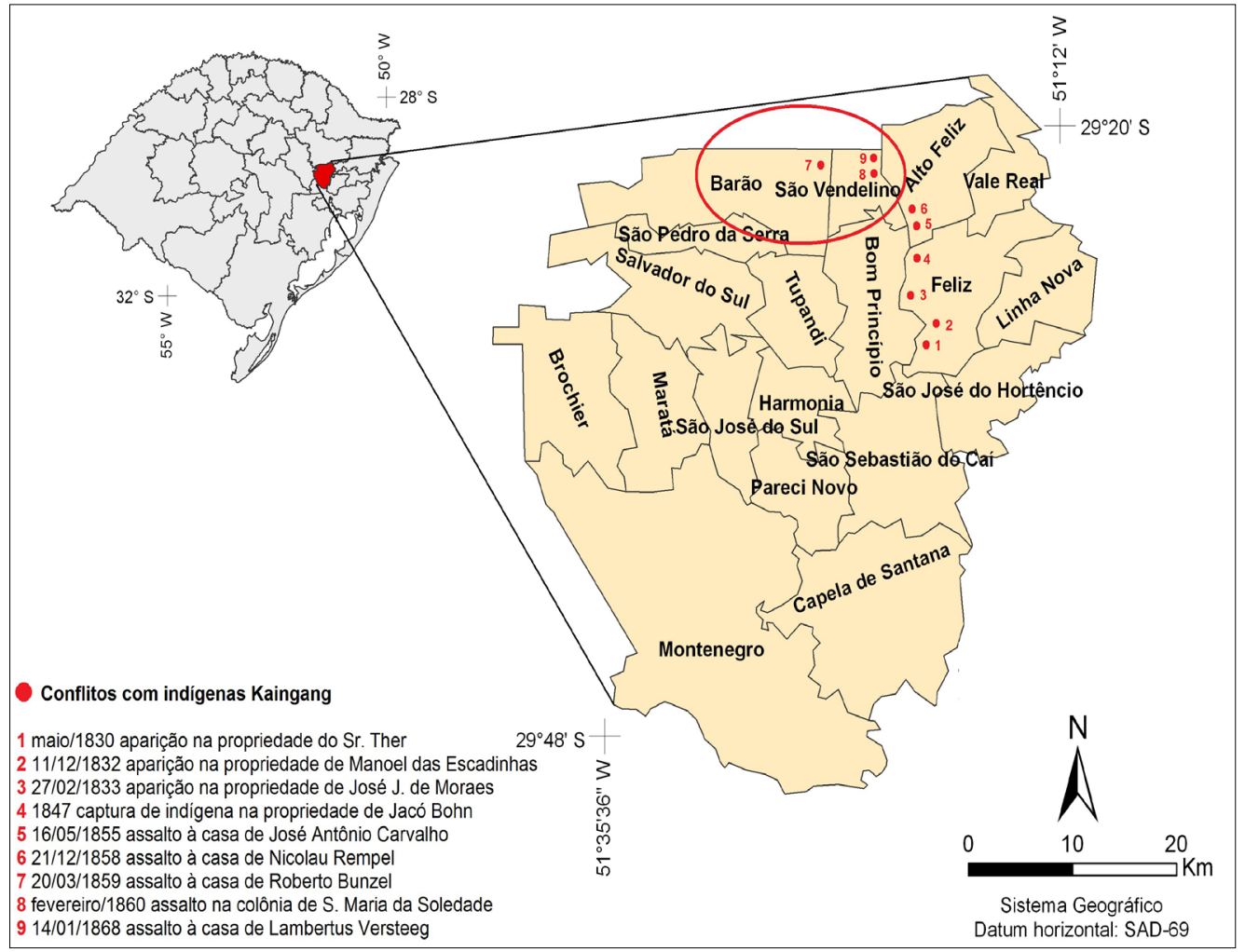

Fonte: Elaborado pelos autores a partir do mapa da Fundação Estatística e Econômica, do Cored do Vale do Caí.

Uma das famílias que se envolveu em situações conflituosas com indígenas foi a família Versteeg, popularmente conhecida em virtude do "rapto" e "pilhagem" provocados por indígenas Kaingang em sua propriedade, na Colônia de Santa Maria da Soledade, no ano de 1868, ilustrado no item 9 do Mapa (Figura 2). O caso teve expressiva repercussão na comunidade, servindo como tema para as clássicas obras dos autores Gansweidt, "As vítimas do Bugre" ([1929] 1946) - do original, "Luis Buger und die Opfe seiner Rache", e Barbosa, "Luís 
Bugre: O indígena diante dos imigrantes alemães" (1977), as quais apresentam alguns detalhes divergentes ${ }^{20}$ entre si acerca do caso.

Gansweidt ([1929] 1946) descreve Lambertus como oriundo de uma nobre família europeia, descendente dos Condes de "von Ameringen", por parte de sua mãe. Seu sobrenome seria originalmente grafado como "von Steg", cuja alteração para a variante "Versteeg" teria sido proposital. Igualmente, teria conhecido sua esposa na Holanda, onde teria adoecido e perdido suas riquezas. Barbosa (1977) reporta-se a Lambertus como proveniente da cidade alemã de Coblença, descendente de uma família nobre. Tendo perdido riquezas e posição social, migrou para a Holanda, onde constituiu família e mais tarde partiu para o Brasil.

Apesar das generalizações presentes nas referidas obras, esta pesquisa permitiu concluir que a família Versteeg era uma das famílias holandesas que foram contratadas pela Sociedade Montravel Silveira e Cia para colonizar a Colônia de Santa Maria da Soledade no ano de 1858. Na sequência, transcreve-se o registro de entrada da família, com vistas para a variação do sobrenome ${ }^{21}$ e a incoerência da procedência, ali atestada como prussiana.

VETZSTEG, Lambert, 22-30, cas., pedreiro; Maria, 22-30, cas.; Jacob, 0-6; pruss; chegada de Rio Grande neste Porto: 3-10-1858, emb.: Continentista (vapor); destino: Santa Maria da Soledade. Obs.: Provenientes do navio Laura de Antuérpia, introduzidos por Montravel Silveira e Cia. (CÓDICE 234, n. 56-58, p. 47, grifo nosso).

Sobre a procedência de Lambertus Versteeg, a partir da documentação, é possível constatar que não foi alemã, como mencionada por muitos autores. Conforme seu registro de nascimento, nasceu em 11 de novembro de 1822, em

20 A obra escrita pelo cônego Matias José Gansweidt e publicada pela primeira vez no ano de 1929, teve grande preocupação em comprovar a veracidade dos fatos. Neste intuito, o religioso firmou uma declaração com o próprio Jacob Lambertus Versteeg, escrita em alemão e datada de 03 de outubro de 1928, em que Versteeg atesta a participação nos relatos e concede a autorização do uso dos mesmos para a referida obra. Ainda assim, durante a narrativa, é possível notar que fizera uso de diferentes fontes, inclusive de documentações/cartas da época.

21 A partir da documentação manuseada, é possível notar que os sobrenomes de origem holandesa no Rio Grande do Sul possuem incoerência quanto à grafia utilizada originalmente na Holanda. Supõe-se que uma justificativa para isto seja a incompreensão dos Padres/Pastores e Oficiais de registros, não habituados com a pronúncia das variedades linguísticas destes imigrantes. Neste trabalho, fez-se uso da grafia "Versteeg", empregada em registros atinentes aos referidos imigrantes na Holanda. 
Relações interétnicas: (des)encontros entre Kaingang e imigrantes holandeses no século XIX em territórios das bacias hidrográficas Taquari-Antas e Caí, Rio Grande do Sul

Haarlem, Província de Noord-Holland, na Holanda, filho de Jacob Versteeg e Maria Wydogen. Corrobora com essa possível procedência, um trecho do registro de nascimento de Lambertus em idioma holandês, oriundo do registro Civil da cidade de Haarlem, capital da Província holandesa de Noord-Holland.

Den twaalfden dag der maand November van't jaar achttien-honderd-tweeen-twintig, ten twaalfuren op den middag.

Acte van geboorte van Lambertus, geboren den Elften, des morgens ten zes uren, Zoon van Jacob Versteeg, van vijftwintigjaren [...], en Maria Wydogen, Ehtaliaden, wonende in da Breesteeg. [...] Zijnde deze Acte na mijne voorlezing geteekend door den Vader en de beide getuigen, bevestigd, ingevolge de wet door mij ondergeteekende Burgemeester, Ambtenaar van den Burgerlijken Stand der stad Haarlem. (LIVRO DE REGISTRO CIVIL... 1822, p. 151, grifos nossos) ${ }^{22}$.

Igualmente, tem-se o registro de óbito do imigrante Lambertus, proveniente da Entidade Eclesiástica IECLB São Vendelino, originalmente no idioma alemão, ocorrido em 1 을 de dezembro de 1887, que menciona sua proveniência holandesa: "Lambert Ver Steeg, geb. 11 Nov. 1822 zu Haarlem in Niederland, gestorben am Lungentzündung am 1 Dez. 1887, Heute, 12 Uhr, beerdigtam 3. Dez ${ }^{23 \prime \prime}$.

O conflito com os Kaingang, que acarretou o aprisionamento dos integrantes da família Versteeg, teria ocorrido após quase dez anos da instalação da família na Colônia de Santa Maria da Soledade. Lambertus teria se afastado da família em 13 de janeiro de 1868, para deslocar-se ao Vale do Caí - São José do Hortêncio, onde visitaria a família de um amigo de nome Valentim Weber, para participar dos festejos atinentes à quermesse ${ }^{24}$, que ocorreria no dia seguinte.

Durante esse período de afastamento, a esposa de Lambertus, referida na obra de Gansweidt ([1929] 1946) como Valfrida Bloom ${ }^{25}$, teria sido atacada por

22 Ao décimo segundo dia do mês de novembro do ano de mil oitocentos e vinte e dois, doze horas ao meio-dia. Ato de nascimento de Lambertus, nascido aos onze dias, pela manhã às seis horas, filho de Jacob Versteeg, de vinte e cinco anos [...], e Maria Wydogen, moradora de Breesteeg. [...] Esta Lei foi assinada depois de minha leitura, pelo pai e pelas duas testemunhas, confirmada pelo Prefeito, assinado por mim, Oficial do Estado Civil da Cidade de Haarlem (tradução dos autores).

23 IECLB São Vendelino, Óbitos (1872-1999), n. 46, grifos nossos.

24 Por quermesse, entende-se que sejam os festejos paroquiais realizados anualmente pelas instituições religiosas.

25 O nome da esposa de Lambertus Versteeg aparece com distintas grafias, variando entre autores e documentos. 
uma parcialidade de indígenas Kaingang, que adentraram a residência e levaram como prisioneiros dois de seus filhos: Jacob Lambertus, de 14 anos e Maria Lucila, de 12 anos. O regresso de Lambertus com os notórios sinais da investida Kaingang é descrito por Gansweidt da seguinte forma:

[...] e vê-se a patear no meio das cinzas onde ainda fumegam carvões acesos. [...] Aqui uma galinha estraçalhada... mais uma... e uma terceira... quarta, quinta, às dúzias juncam o chão em meio as penas. Avança mais... os chiqueiros arrombados e em parte demolidos. Dentro, os suínos abatidos, cortados, esquartejados e com nacos e quartos desaparecidos. Segue para o potreiro e a visão dantesca se repete. Cavalos, vacas, bois, terneiros, tudo destroçado a cacetadas, golpeando até a morte. Aqui também faltam às vítimas diversas partes do corpo. E em toda parte, no chão, pegadas humanas, de pés descalços, mas pegas diferentes das de seus familiares, mais largas, grosseiras e rudes. (GANSWEIDT, [1929] 1946, p. 59).

Sendo assim, Lambertus procurou apoio de seus vizinhos, que compuseram uma expedição inicial de vinte e seis colonos, com o intuito de localizar a família em meio à mata. A incursão, que teria durado dois dias - com pernoite e enfrentando chuvas na floresta, teria chegado ao fim com o esgotamento físico dos colonos, sem maiores resultados. Na sequência, Lambertus teria buscado auxílio em São Leopoldo, organizando-se uma segunda expedição, esta, com participação do Chefe de Polícia de Porto Alegre e demais colonos de distintas procedências da Província. Nessa segunda incursão na mata, Gansweidt relata que os "expedicionários" teriam chegado muito próximos do grupo Kaingang, que estava com a família aprisionada:

Não parece dúvida! Aqui houve uma aldeia um dia. No centro de um relvado pisoteado negreja um montão de cinzas. Ao derredor, espaços retangulares de terra nua, em meio do capim, dizem que aí se erguiam ocas selvagens. Ainda abertos os buracos dos postes arrancados. Palha e ramagem sêca, pertencentes aos telhados e paredes, jazem esparsos pelo chão. Bem recente a demolição, por certo, pois ainda nenhuma chuva batizara a cinza. (GANSWEIDT, [1929] 1946, p. 127).

Esta segunda expedição - que partira em 22 de janeiro de 1868 - teria chegado à Fazenda de Manoel Firminiano, que acolheu os integrantes por dois dias e apoiou a incursão nas matas por mais dez dias, inclusive, fornecendo peões. Mesmo assim, a expedição, que se alongou por vinte e três dias, não atingiu resultados satisfatórios, conforme comprova o relatório enviado pelo Presidente da 
Relações interétnicas: (des)encontros entre Kaingang e imigrantes holandeses no século XIX em territórios das bacias hidrográficas Taquari-Antas e Caí, Rio Grande do Sul

Província Dr. Francisco Marcondes Homem de Melo à administração da Província, datado de 24 de fevereiro de 1868:

[...] Por offcio de 24 de Fevereiro comunicou-me o Dr. Chefe da Polícia que forão infrutiferas as diligencias empregadas, pois apenas se encontrarão vestígios passageiros da marcha dos selvagens, despendendo-se com a partida que, desde 19 de Janeiro até 11 de Fevereiro se internou nas mattas, a quantia de $701 \$ 740$ reis, que mandei pagar pela Directoria da Fazenda Provincial. (RELATÓRIO de 24/02/1868, AHRS).

O personagem Luís Bugre ${ }^{26}$, junto com a família Versteeg, foi um dos protagonistas das obras de Ganweidt e Barbosa, sendo um indivíduo atuante nessa história. Também residia na Colônia de Santa Maria da Soledade e, inclusive, participou da segunda expedição montada para resgatar os integrantes da família aprisionada. Sobre ele, Gansweidt descreve:

Vagueia pela floresta ou visita as vendas destes rincões, trocando objetos, enquanto deixa mulher e um par de filhinhos aos próprios cuidados. Em qualquer parte que vá, o acompanha uma forte matilha de cães ferozes que o fazem deveras temido. Menos de uma dúzia nunca o cercam. Mas, justiça Ihe seja feita: tem os bichos na mão, atendem prontamente ao seu assovio e temem mais sua voz que seu chicote. (GANSWEIDT, [1929] 1946, p. 41).

Com sua identidade de indígena Kaingang, mas convivendo no mundo dos não índios, aos poucos, Ihe é atribuída uma concepção negativa, sendo inclusive insinuado, nas obras já mencionadas, o seu envolvimento na incursão Kaingang envolvendo a família Versteeg, atribuindo-Ihe, inclusive, o retardo da expedição da qual participou. Nesse sentido, Gansweidt retratou a face negativa de Luís Bugre através da fala do Delegado:

A mim me parece que os bugres andam com êle de mãos dadas. Suas respostas de moleque, que mais foram do que prova de malícia e arrogância? Sem dúvida, pensa ele que estamos já meio em seu poder e dependemos de sua misericórdia. Claro que o tratante tem das suas na mioleira. Odeia-

26 Conforme Gansweidt ([1929] 1946), Luís Bugre teria sido capturado na propriedade de Jacó Bohn em Feliz - conforme indica o item 4 do mapa (Figura 2) - com entorno de onze anos de idade. Na oportunidade, indígenas teriam se aproximado da plantação de milhos do referido colono, que ao os notar, chamou os demais vizinhos. No conflito, um jovem índio teria desarticulado o joelho e sido tomado como escravo de Matias Rodrigues da Fonseca. Da mesma forma, teria aprendido a falar alemão e sido batizado na fé Católica em São José do Hortêncio. 
nos, bem no dizem seus olhos. Cuidado! Não vamos cair nas ciladas desse vagabundo... (GANSWEIDT, [1929] 1946, p. 128).

Sobre o destino final da família Versteeg, Gansweidt ([1929] 1946) evidencia em sua obra que Valfrida teria sido morta por indígenas através de agressões e flechadas, em cujo destino em sequência a filha Maria Lucila também teria sido, embora seu desaparecimento não fique claro na história. Segundo Laroque (2000), o filho Jacob Lambertus Versteeg teria sido cogitado para atuar como liderança indígena, pelo Cacique da parcialidade Kaingang, com a qual estava convivendo; entretanto teria fugido durante uma festividade indígena, sendo acolhido por um rico estancieiro de nome Adolfo Pacheco. Lambertus Versteeg, que teria vendido sua propriedade em Santa Maria da Soledade e que estaria empregado em uma companhia de navegação fluvial, é encontrado mais tarde pelo filho Jacob. Barbosa (1977) relata que a morte de Valfrida teria ocorrido com forte violência, mas deixa vagas as causas do desaparecimento da filha Maria Lucila. O desfecho da história, no que diz respeito à fuga de Jacob e ao reencontro com o pai, assemelha-se às informações fornecidas por Gansweidt.

No que diz respeito à questão identitária, é interessante ressaltar que a Colônia de Santa Maria da Soledade - em sua composição heterogênea- possibilitou que indivíduos assumissem identidades distintas da sua, ou até mesmo múltiplas, como é o caso de Jacob Lambertus Versteeg, imigrante holandês, criado entre alemães e que compartilhou experiências com indígenas Kaingang em sua infância. Igualmente e talvez mais expressivo seja o caso de Luís Bugre, proveniente do grupo étnico indígena Kaingang, capturado na infância por colonos europeus, passando de "bugre" 27 para uma posição de ex-selvagem na sociedade em que estava inserido.

A partir de Woodward (2004), entende-se que a identidade é produzida por sistemas de representação que dão sentido à experiência do indivíduo e à sua constituição enquanto ser. Ou seja, a identidade é formada e transformada em relação às formas pelas quais o indivíduo é representado nos sistemas culturais que o rodeiam.

27 Segundo Becker (1995), a palavra bugre significa uma denominação genérica atribuída à um grupo de indígenas que habitava as matas do Rio Grande do Sul, sugerindo também o intuito de diferenciá-los do grupo Guarani. 
No que tange à concepção do "outro", num primeiro momento ligada ao indígena em virtude da discriminação e do seu distanciamento cultural em relação ao indivíduo europeu, não deve ser por si só considerado o "outro". Entende-se que esta posição social carregada de indiferença e inferioridade recai com o mesmo teor sobre o elemento europeu partindo do indígena, pois, conforme referido, os Kaingang também desenvolveram um comportamento repulsivo no momento em que passaram a "perder" seus tradicionais territórios para o elemento colonizador. Sendo assim, o "alemão" também pode assumir a posição de "outro" no contexto das relações interétnicas.

Nesse sentido, Dornelles (2011), analisando a posição de "bugre" no meio social, atesta que a referida categoria pode não designar um grupo específico, como, por exemplo, os indígenas, mas, sim, significar algo mais amplo, como a "indianização" de imigrantes europeus, como foi a experiência de Jacob Lambertus Versteeg; logo, "[...] não se nasce bugre, estes são feitos/criados na história" (DORNELLES, 2011, p. 70), ou seja, trata-se de uma construção social.

Mesmo assim, no âmbito das relações interétnicas, deve-se ressaltar que a interação entre grupos indígenas e imigrantes europeus não se deu somente de forma conflituosa, através de "ataques" e "pilhagens", termos etnocêntricos que geralmente constam nos relatos. Esta interação também ocorreu a partir de alianças entre indígenas Kaingang e o governo da Província, a exemplo do ocorrido na Colônia Santa Maria da Soledade, em 1857, em que Madame Langedonck refere-se a um guia na posição de ex-selvagem, que se entende tratar-se do próprio Luís Bugre:

O guia que veio buscar-nos no dia seguinte era um ex-selvagem. Permanecera até a idade de dezesseis anos na tribo onde nascera. Ignoro que circunstâncias o haviam quase civilizado. Ele se colocara a serviço da Sociedade, sem ocupação especial, pois um trabalho regular Ihe era singularmente antipático. [...] Um dia alguém colocou em dúvida a faculdade que se atribuía a Antônio Luís, (era esse o nome do guia) [...]. (LANGENDOCK, [1862] 2002, p. 44).

Nesse sentido, no âmbito das relações interétnicas, e tendo por base Oliveira (1976), entende-se que as relações mantidas entre indígenas e europeus, em todas as suas modalidades de relações interétnicas, tiveram significados diferentes para cada uma das concepções culturais, visto que, tendo significativas distinções entre si, estavam em posição de afirmar-se diante da cultura alheia. 


\section{CONSIDERAÇÕES FINAIS}

O presente estudo possibilitou constatar que os territórios correspondentes às Bacias Hidrográficas Taquari-Antas e Caí, Rio Grande do Sul, foram povoados por numerosos grupos étnicos, culturalmente distintos, no caso, indígenas, africanos e negros escravizados, europeus e seus descendentes. Nesse sentido, nota-se uma invisibilização de grupos que, da mesma forma que os demais, foram personagens constantes no processo de constituição da Província de São Pedro do Rio Grande do Sul e na ocupação dos territórios das Bacias Hidrográficas Taquari-Antas e Caí.

Igualmente, notou-se um emprego generalizante da denominação "imigração alemã" pela historiografia tradicional, tendo atuado de forma a homogeneizar uma gama de imigrantes oriundos de diferentes regiões da Europa, com aspectos culturais bastante distintos, como língua, crenças e costumes, embora introduzidos no mesmo período histórico.

Esta falta de reconhecimento das diferenças culturais é perceptível na forma como foi conduzido o projeto de expansão do Império brasileiro no século XIX, que avançou sobre tradicionais territórios indígenas, neste caso, da etnia Kaingang, no intuito de colonizar áreas consideradas desabitadas. Assim, imigrantes que foram compulsoriamente instalados sobre assentamentos indígenas passaram a estabelecer relações com grupos portadores de concepções culturais extremamente distantes da sua.

Entre esses imigrantes, destacaram-se os holandeses, contratados para ocuparem as ditas "terras devolutas", sendo estabelecidos em colônias em formação na Província de São Pedro do Rio Grande do Sul, com maior intensidade, na Colônia de Santa Maria da Soledade. Estes imigrantes, frequentemente tratados como alemães, compuseram parte da expressão generalizante já mencionada.

Nesse contexto de colonização, ocorreram os (des)encontros culturais entre Kaingang e holandeses, manifestados, na maioria das vezes, de forma conflituosa, como foi o caso da Família Versteeg, que repercute no imaginário social até os dias atuais. Essas relações interétnicas, que resultaram do encontro de distintas etnias no mesmo território, tiveram significados diferentes para cada uma das concepções culturais envolvidas. 
Relações interétnicas: (des)encontros entre Kaingang e imigrantes holandeses no século XIX em territórios das bacias hidrográficas Taquari-Antas e Caí, Rio Grande do Sul

\section{VINCULAÇÃO}

O estudo insere-se no Projeto de Pesquisa "Identidades étnicas em espaços territoriais da Bacia Hidrográfica do Taquari-Antas/RS", vinculado ao PPG em Ambiente e Desenvolvimento e conta com auxílios financeiro da Universidade do Vale do Taquari (Univates) e da Fundação de Amparo à Pesquisa do Estado do Rio Grande do Sul (Fapergs).

\section{REFERÊNCIAS}

AMSTAD, Theodor. Cem anos de germaneidade no Rio Grande do Sul (1824-1924). Tradução de Arthur Blasio Rambo. São Leopoldo: Ed.Unisinos, [1924] 1999.

BARBOSA, Fidélis Dalcin. Luís Bugre: o indígena diante dos imigrantes alemães. Passo Fundo: EST Edições,1977.

BARTH, Frederik. Os grupos étnicos e suas fronteiras. In: BARTH, Frederik; LASK, Tomke (Org.). O guru, o iniciador e outras variações antropológicas. Tradução de John Cunha Comerford. Rio de Janeiro: Contracapa, 2000. p. 25-67.

BECKER, Ítala Irene Basile. O índio Kaingáng no Rio Grande do Sul. São Leopoldo, RS: Instituto Anchietano de Pesquisas/UNISINOS, 1995.

CHRISTILLINO, Christiano. Estranhos em seu próprio chão: o processo de apropriações de terras na Província de São Pedro do Rio Grande do Sul (o Vale do Taquari no período 18401889). 2004. 374 f. Dissertação (Mestrado em História da América Latina) - Universidade do Vale do Rio dos Sinos (UNISINOS), São Leopoldo, RS, 2004.

CÓDICE 234. Registro de Entrada da família de Francisco Alberg, de 28 de novembro de 1858. Livro de registros de colonos chegado à Província de São Pedro do Rio Grande do Sul (1857-1863). Arquivo Histórico do Rio Grande do Sul (AHRS). Fundo Imigração, Terras e Colonização, n. 6-10, p. 64.

CÓDICE 234. Registro de Entrada da família de João Dierings, de 5 de setembro de 1858. Livro de registros de colonos chegado à Província de São Pedro do Rio Grande do Sul (1857-1863). Arquivo Histórico do Rio Grande do Sul (AHRS). Fundo Imigração, Terras e Colonização, n. 40-48, p. 43.

CÓDICE 234. Registro de Entrada da família de Lambert Vetzsteg, de 3 de outubro de 1858. Livro de registros de colonos chegado à Província de São Pedro do Rio Grande do 
Sul (1857-1863). Arquivo Histórico do Rio Grande do Sul (AHRS). Fundo Imigração, Terras e Colonização, n. 56-58, p. 47.

CÓDICE 313. Livro de lotes da Ex-Colônia Santa Maria da Soledade. Fundo Imigração, Terras e Colonização. Arquivo Histórico do Rio Grande do Sul (AHRS). Porto Alegre, [s.d.].

CONTRATO de 6 de fevereiro de 1855. Fundo Imigração, Terras e Colonização, maço 35, caixa 20. Arquivo Histórico do Rio Grande do Sul (AHRS). Porto Alegre, [s.d.].

CONTRATO de 30 de dezembro de 1854. Fundo Imigração, Terras e Colonização, maço 35, caixa 20, Arquivo Histórico do Rio Grande do Sul, Porto Alegre, [s.d.].

CORREA, Sílvio Marcus de Souza. Multiculturalismo e fronteiras étnicas. In: BOEIRA, Nelson; GOLIN, Tau (Coord.). Império. Passo Fundo: Méritos, 2006.

DORNELLES, Soraia Sales. De Coroados a Kaingang: as experiências vividas pelos indígenas no contexto da imigração alemã e italiana no Rio Grande do Sul do século XIX e início do XX. Orientador: Eduardo Santos Neumann. 2011. 134 f. Dissertação (Mestrado em História) - Universidade Federal do Rio Grande do Sul (URGS), Porto Alegre, RS, 2011.

GANSWEIDT, Matias José. As vítimas do Bugre. Porto Alegre: Selbach, 1946.

IECLB. Registro de Óbito de Lambert Ver Steeg, de 1으 de dezembro de 1887. Acervo Genealogia RS. Livro de Registros Eclesiásticos - Óbitos (1872-1999), IECLB São Vendelino, n. 46. [S.d.].

IECLB. Registro de Casamento de Christian te Roller, de 18 de abril de 1876. Acervo Genealogia RS. Livro de Registros Eclesiásticos - Casamentos (1862-1864), IECLB São Vendelino, n. 13, p. 341. [S.d.].

IBGE. Mapa da Fundação Estatística e Econômica, do Cored do Vale do Caí. 2009. Disponível em: http://mapas.fee.tche.br/wp-content/uploads/2009/08/corede_vale_ do_cai_2008_municipios.png. Acesso em: 22 ago. 2017.

LANGENDONCK, Madame van. Uma colônia no Brasil. Tradução de Paula Berinson e introdução de Augusto Meyer. Florianópolis: Editora Mulheres, [1862] 2002.

LARAIA, Roque de Barros. Cultura: um conceito antropológico. Rio de Janeiro: Jorge Zahar Editor, 2003.

LAROQUE, Luís Fernando da Silva. Lideranças Kaingang no Brasil Meridional (18081889). São Leopoldo: Instituto Anchietano de Pesquisas/Unisinos, 2000. (Série Pesquisas - Antropologia, v. 56). 
Relações interétnicas: (des)encontros entre Kaingang e imigrantes holandeses no século XIX em territórios das bacias hidrográficas Taquari-Antas e Caí, Rio Grande do Sul

LAROQUE, Luís Fernando da Silva. Os Kaingangues- momentos de historicidades indígenas. In: BOEIRA, Nelson; GOLIN, Tau (Coord.). História geral do Rio Grande do Sul - povos indígenas. Passo Fundo: Méritos, 2009. p. 81-108. (V. 5).

LIVRO DE REGISTRO CIVIL - nascimentos (1821-1822). Registro de nascimento de 11 de novembro de 1822. Haarlem, Noord-Holland, Netherland, p. 151. Family Search. Disponível em: https://www.familysearch.org/ark:/61903/3:1:939Z-RTJH-2?i=341\&wc=MCLW-HMH \%3A341396101\%2C341773201\&cc=2020117. Acesso em: 22 ago. 2017.

MABILDE, Pierre. F. A. Booth. Apontamentos sobre os indígenas selvagens da Nação dos Coroados dos Matos da província do Rio Grande do Sul-1836-1866. São Paulo: IBRASA, 1983.

MARTINS, José de Souza. Fronteira: a degradação do outro nos confins do humano. São Paulo: Hucitec, 1997.

OLIVEIRA, Roberto Cardoso de. Identidade, etnia e estrutura social. São Paulo: Pioneira, São Paulo, 1976.

PIRES, Karen Daniela. O trabalho escravo e suas implicações na paisagem urbana e rural de Taquari, Estrela e Santo Amaro/RS - final do século XIX. Orientadora: Neli Teresinha Galarce Machado. 2016. 182 f. Dissertação (Mestrado em Ambiente e Desenvolvimento) - Centro Universitário Univates, Lajeado, RS, 2016.

RELATÓRIO de 24 de fevereiro de 1868. Relatório da Diretoria Geral dos Índios. Arquivo Histórico do Rio Grande do Sul (AHRS). Porto Alegre, [s.d.].

RIEL, Cornelia Van; ZART, Helaine Gnoatto. A caminho da esperança: imigração holandesa de Não-Me-Toque. Não-Me-Toque, RS: RH Publicidades Ltda., 2011.

ROCHE, Jean. A colonização Alemã e o Rio Grande do Sul. Porto Alegre: Globo S.A., 1969. (V. I).

ROOS, Ton; ESHUIS, Margje. Os capixabas Holandeses - uma história holandesa no Brasil. Barneveld, Países Baixos: Editora Koninklijke BDU Uitgevers, 2008.

SECRETARIA DO MEIO AMBIENTE E INFRAESTRUTURA (SEMA). Bacias hidrográficas do Rio Grande do Sul. 2017. Disponível em: https://www.sema.rs.gov.br/bacias-hidrograficas. Acesso em: 22 ago. 2017.

VEDOY, Moisés Ilair Blum. Contatos interétnicos: sesmeiros, fazendeiros, imigrantes alemães e indígenas Kaingang em territórios das bacias hidrográficas do Taquari-Antas e Caí. Orientador: Luís Fernando da Silva Laroque. 2015. 100f. Monografia (Graduação em História) - Centro Universitário Univates, Lajeado, RS, 2015. 
VOLKSBLATT, Deutsches. Ein Brief aus dem Jahre 1832. Instituto Anchietano de Pesquisas São. Leopoldo, 1o maio 1934.

WOLF, Sidnei. Arqueologia Jê no alto Forqueta/RS e Guaporé/RS: um novo cenário para um antigo contexto. Orientadora: Neli Teresinha Galarce Machado. 2016. 341 f. Tese (Doutorado em Ciência: Ambiente e Desenvolvimento) - Centro Universitário Univates, Lajeado, RS, 2016.

WOODWARD, Kathryn. Identidade e diferença: uma introdução teórica e conceitual. In: SILVA, Tomaz Tadeu; HALL, Stuart; WOODWARD, Kathryn (Org.). Identidade e diferença: a perspectiva dos estudos culturais. Tradução de Thomaz Tadeu da Silva. Petrópolis, RJ: Vozes, 2004. p. 7-72.

\section{Sobre os autores:}

Luís Fernando da Silva Laroque: Doutor em História. Professor e pesquisador do Programa de Pós-Graduação em Ambiente e Desenvolvimento e do Curso de Graduação em História da Universidade do Vale do Taquari (Univates), Lajeado, RS, Brasil. E-mail: Iflaroque@univates.br

Tiago Weizenmann: Doutor em História. Professor da Área das Humanidades, e vinculado às pesquisas do Programa de Pós-Graduação em Ambiente e Desenvolvimento da Univates. E-mail: tweizenmann1@univates.br

Jéferson Luís Schäeffer: Graduando do Curso de Licenciatura em História. Bolsista de Iniciação científica da Univates. E-mail: jeferson.schaeffer@universo.univates.br

Recebido em: 30 de junho de 2018

Aceito para publicação em: 22 de novembro de 2018 